\title{
CONSIDERAÇÕES SOBRE A PESQUISA ARQUEOLÓGICA NA ÁREA URBANA DE BARUERI
}

O objetivo do projeto Levantamento das estruturas arqueológicas do antigo aldeamento de Barueri é pesquisar e resgatar os vestígios arqueológicos resultantes desta ocupação que permaneceram sob o pavimento urbano atual. A área, que hoje é conhecida como Aldeia, tem sido ocupada de forma contínua desde o século $\dot{X}$ VI (sem levar em conta possíveis ocupações anteriores), e as evidências do antigo aldeamento, após terem sofrido constantes interferências antrópicas e naturais, foram totalmente destruídas. Não existe atualmente nenhuma evidência superficial que testemunhe o processo de ocupação do local, com exceção da capela, que constitui o único elemento relacionado ao antigo aldeamento jesuítico.

Trata-se de uma área culturalmente descaracterizada, na qual o levantamento das estruturas arqueológicas do antigo aldeamento corresponde a uma atitude importante no sentido de ter como objeto de estudo uma área urbanizada, cujo potencial como fonte de informação histórica já tinha sido descartado. ${ }^{1}$

O sítio enfocado está localizado no topo de uma colina, às margens do rio Tietê, em um setor onde o rio foi desviado em decorrência de obras de retificação do seu leito.

O padrão de ocupação do antigo aldeamento corresponde àquele que tem sido observado na maioria das aldeias do período pré-cabralino, que se encontram em terreno alto, com ampla vista dos arredores e nas proximidades de cursos d'água.

A respeito da caracterização geográfica, "Barueri localizou-se justo na área em que o Tietê abandona a faixa sedimentar para penetrar na zona cristalina, portanto numa

(1) Não estamos utilizando o termo arqueologia urbana, mas reconhecemos a especificidade do meio urbano, bem como o envolvimento da pesquisa arqueológica realizada na cidade e a relação com a comunidade. área de contato geológico e, secundariamente, morfológico. Nessa área, o rio, entre outros de expressão variada, forma um grande meandro: correndo inicialmente para oeste, volta-se para o norte ao penetrar nas superfícies cristalinas. $O$ aldeamento sediouse justamente a jusante do ponto em que o rio se volta para o norte, junto à margem direita, sobre um nítido terraço $(730 \mathrm{~m})$ a cavaleiro do rio, em local fronteiro à desembocadura do afluente Barueri. Enquanto a margem esquerda, nesse trecho, é baixa, dada a deposição de sedimentos carreados pelo Barueri, a margem direita é alta, a barranca do rio correspondendo ao talude do terraço atualmente trabalhado pelas águas.

Abrigado de possiveis inundações em virtude de sua localização sobre o terraço, Barueri pôde, entretanto, usufruir de todas as vantagens da contigüidade do rio, tanto que, certamente, deve ter tido um atracadouro para o qual se descia por intermédio de uma breve e ingreme ladeira a partir da praça" (Petrone 1995:145).

Além destes aspectos considerados, as construções realizadas pelos jesuítas na época da fundação da Aldeia de Barueri deveriam seguir o disposto nas Leis das Índias, mas deve-se levar em conta toda sorte de fatores que possam ter impedido o projeto inicial. A localização das estruturas levantadas vai fornecer dados soḅre a relação entre a intenção inicial e o efetivamente ocorrido. ${ }^{2}$

$\mathrm{O}$ resgate da cultura materialı, atravěs de pesquisas arqueológicas sistemáticas, permitirá destacar a importância do município de Barueri para o desenvolvimento da história brasileira, fundamentada na preservação dos vestígios físicos que constituem um elo

(2) Uma referência iconográfica é a planta da aldeia de Carapicuíba feita de acordo com o levantamento feito em 1937, onde o autor reproduz a planta de uma Aldeia Jesuítica projetada de acordo com as Leis das Índias. 
importante para o entendimento do passado e a valorização das tradições ainda existentes.

O resultado da pesquisa vai possibilitar que o município de Barueri possa conhecer, e estabelecer a partir deste conhecimento, uma política de gerenciamento do patrimônio arqueológico, visando o seu uso social e o aproveitamento dentro de projetos de turismo cultural. Este último está situado entre as atividades que vêm se destacando como uma das principais fontes de geração de recursos econômicos e para a arqueologia significa uma forma de garantir a manutenção da integridade do patrimônio cultural.

A caracterização histórica mostra a origem da ocupação da região com o estabelecimento do aldeamento indígena, que teria sido fundado pelos jesuítas em 1560, não existindo documentação sobre uma ocupação indígena anterior. Dados sobre a sequiência da ocupação humana no atual município de Barueri poderão ser levantados posteriormente com a ampliação da área da pesquisa arqueológiça.

$\mathrm{O}$ estudo dos aldeamentos paulistas passa, também, pela análise do processo de ocupação da terra comandado pelos europeus, pela utilização da mão-de-obra nativa - através, na maioria das vezes, de uma "escravidão" disfarçada, pela sobrevivência de uma série de hábitos, atividades e atitudes, caracterizando o elemento étnico típico dos arredores de São Paulo.

Outra preocupação, sempre presente nos estudos referentes aos aldeamentos dos primeiros séculos, é o do contingente indígena que teria passado por esses núcleos de aculturação, da quantidade de nativos vindos através dos descimientos do sertão e do próprio contato entre os bandeirantes e os missioneiros da América Espanhola. Como já é sabido, o Aldeamento de Barueri aparece sempre como o mais importante em termos de concentração demográfica, mas deve-se levar em conta que poderiam existir dois núcleos populacionais distintos em Barueri, o que nos leva a crer que a diversidade étnica era bastante elevada.

A importância da área está no fato de ela ter sido o palco da convivência de representantes de várias tribos, ou mesmo nações indígenas, trocando elementos culturais entre si e com os europeus.
$\mathrm{O}$ aldeamento situa-se no ponto final de navegação do Alto Tietê, que só volta a ser navegável a partir do atual município de Itu, o que faz com que Barueri seja a etapa inicial do trecho terrestre que demanda para o oeste. Além disso, existe uma vasta documentação referente ao caminho dos indígenas - o Peabiru - que levaria às minas situadas no território espanhol de outrora (o lendário $E l$ Dorado - que não era senão as minas de prata de Potosi). Se o antigo aldeamento tiver sido instalado às margens dessa trilha indígena, poderemos, através das pesquisas arqueológicas, constatar ocupação anterior à chegada dos europeus.

Do ponto de vista conceitual consideramos que todas as atividades e ações do Homem deixam algum tipo de marca ou de vestígio no solo de atuação, cuja análise possibilita a reconstituição da dinâmica social passada. Acreditamos que com a aplicação de uma metodologia de levantamento e com técnicas de escavação apropriadas para áreas urbanas será possível recuperar os remanescentes das estruturas do antigo aldeamento.

O levantamento prévio realizado sobre os aldeamentos de São Paulo e especialmente o de Barueri, mais a análise antropológica sobre o comportamento e a relação dos grupos indígenas envolvidos com os religiosos responsáveis pelo aldeamento, permitiram os primeiros questionamentos teóricos a serem testados em campo.

A possibilidade da utilização da documentação textual vem reforçar os dados para a interpretação do registro arqueológico. Neste caso, este reforço de informação será fundamental, uma vez que os vestígios do antigo aldeamento foram sendo destruídos sistematicamente ao longo dos anos pela instalação das novas comunidades e pela ação natural do clima.

As prospecções serão iniciadas nas áreas não con truídas, nas proximidades da capela, ${ }^{3}$ local que poderia ter sido o centro do aldeamento. A localização dos alicerces das cons-

(3) A capela de Nossa Senhora da Escada também será alvo de intervenção arquitetônica de restauro após a conclusão da pesquisa arqueológica. 
truções, ou de vestígios de taipa, vão determinar a orientação da decapagem, pois a proposta é expor ao máximo as estruturas que indiquem o plano original do estabelecimento.

Para a concretização do projeto uma seqüência de atividades será realizada:

\footnotetext{
1 - Levantamento da documentação textual e iconográfica sobre o processo de ocupação do município de Barueri;

2 - Levantamento dos vestígios arqueológicos e etnográficos do antigo aldẹmento na área urbana não edificada;

3 - Levantamento dos vestígios arqueológicos e etnográficos do antigo aldeamento na área urbana edificada;

4 - Divulgação do andamento do trabalho: palestras e publicações;

5 - Elaboração de um programa educativo junto às escolas do município;

6 - Elaboração de um programa de gestão e gerenciamento do patrimônio cultural municipal.
}

A pesquisa em área urbanizada tem que contar com a participação e colaboração da comunidade que, no caso de Barueri, tem mostrado um interesse em recuperar aspectos de sua história.

A elaboração de um programa de gestão e gerenciamento do patrimônio cultural municipal, através tanto da evidenciação de estruturas desaparecidas, quanto da revitalização de edifícios ainda existentes, seria um outro caminho possível para a construção de uma memória histórica sobre Barueri.
Esta postura em relação à história e ao patrimônio é importante, porque, mesmo existindo uma legislação federal que garanta a integridade do patrimônio arqueológico, somente o envolvimento da própria comunidade pode assegurar a sua conservação. Defendemos a inclusão, em qualquer projeto de pesquisa arqueológica, de ações relacionadas com a divulgação, conservação e uso social dos sítios trabalhados. Daí a necessidade de realizar, desde $o$ início da pesquisa, um trabalho de divulgação e conscientização sobre o valor do patrimônio arqueológico, visando a concretização das propostas e a sua manutenção futura.

É exemplar a posição da Prefeitura Municipal de Barueri e da comunidade do bairro da Aldeia, de buscar a origem da sua história no registro arqueológico, ainda que atualmente não exista mais qualquer vestígio superficial. $\mathrm{O}$ convênio realizado entre a Prefeitura Municipal de Barueri e o Museu de Arqueologia e Etnologia da Universidade de São Paulo é o responsável pela execução do projeto.

$\mathrm{O}$ trabalho de parceria entre os órgãos oficiais e a universidade, visando a devolução do conhecimento à comunidade, faz com que a arqueologia cumpra o seu papel social na participação das políticas públicas culturais.

Maria Cristina Mineiro Scatamacchia* Cleide Franchi**

\section{Referências bibliográficas}

PETRONE, P. 1995 Aldeamentos Paulistas. São Paulo:
Edusp.
SAIA, $L$.

1995 Morada Paulista, São Paulo: Ed. Perspectiva, $3^{a}$ edição. Coleção Debates. 